\title{
Pulmonary Coccidioidomycosis That Formed a Fungus Ball with 8-years Duration
}

\author{
Tadashi Osaki, Hiroshi Morishita, Hajime MaEdA*, Katsuhiko KameI**, \\ Shigenori HoshinO, Takashi KIJIMA, Toru KuMAGAI, Mitsuhiro YoshIDA, \\ Isao TACHIBANA and Ichiro KAWASE
}

\begin{abstract}
Coccidioidomycosis, caused by inhaling Coccidioides immitis, is a mycosis imported from endemic regions including the southwestern United States. $C$. immitis is so virulent that even a short-term stay in the endemic area can provide a chance for infection. Here, we report a 33year-old Japanese man with formation of a fungus ball inside the pulmonary cavity secondary to coccidioidomycosis with a duration of $\mathbf{8}$ years, which is considered rare. He was infected with $C$. immitis in the United States in 1996. A nodule remained in the lung, which later cavitated with fungus ball formation. We identified Coccidioides immitis in the cultured specimen from the cavity and serum antibodies against it. We performed a lobectomy in 2003 since anti-fungal treatment was only temporarily effective. He is still free of disease 6 months later.
\end{abstract}

(Internal Medicine 44: 141-144, 2005)

Key words: coccidioidomycosis, Coccidioides immitis, imported mycosis, fungal infection, fungus ball

\section{Introduction}

Pulmonary coccidioidomycosis is caused by inhalation of arthrospores of a virulent fungus, Coccidioides immitis $(C$. immitis), which is endemic primarily in California, Arizona, Nevada, New Mexico and Texas in the United States. The number of infections is estimated as 100,000 every year in the United States. On the other hand, in Japan, only 31 cases had been reported as of 2001 (1). Eighty-seven percent of patients with coccidioidomycosis were infected during a stay in an endemic area. This disease has been designated as a notifiable fungal disease since 1999 . We present a case of fungus ball formation secondary to cavitary coccidioidomycosis diagnosed by fiberoptic bronchoscopy. Cavitary pulmonary disease due to coccidioidomycosis is common; however, development of both an underlying cavity and a fungus ball due to $C$. immitis is rare $(2,3)$.

\section{Case Report}

A 33-year-old Japanese man with complaints of low grade fever and general fatigue was referred to us for further evaluation of a pulmonary cavity increasing in size in the right lower lung field. He had smoked 10 cigarettes daily for 10 years. He had move to Bakersfield, California, in December 1995. While he was there in October 1996, he was found to have right-sided pneumonia, for which he received a course of oral antibiotics (Fig. 1). A serologic test of his blood for anti-coccidioidal antibodies was positive in November 1996. He was immediately started on fluconazole $200 \mathrm{mg}$ daily and the infiltrate soon disappeared. Fluconazole was subsequently discontinued after 6 months. On a visit to Japan in August 1997, a chest radiograph revealed a nodule in the right lung field. However, the patient did not receive further medication because a pulmonary nodule caused by coccidioidomycosis usually disappears within 2 years without treatment [Fig. 1, computed tomograph (CT) in February 1998] (4). However, chest radiograph and CT in June 2001 indicated that the pulmonary nodule had become larger and excavated. The patient visited a hospital in Tokyo for evaluation of his pulmonary lesion. An enzyme-linked method failed to detect antibodies to $C$. immitis and fiberoptic bronchoscopy failed to show $C$. immitis in the specimen isolated from the cavity. The patient was transferred to Osaka in August 2001 for his job. On September

From the Department of Molecular Medicine, Osaka University Graduate School of Medicine, Suita, *Department of Surgery, Toneyama National Hospital, Toyonaka and **Research Center for Pathogenic Fungi and Microbial Toxicoses, Chiba University, Chiba

Received for publication April 9, 2004; Accepted for publication September 12, 2004

Reprint requests should be addressed to Dr. Tadashi Osaki, the Department of Molecular Medicine, Osaka University Graduate School of Medicine, 2-2 Yamada-oka, Suita, Osaka 565-0871 

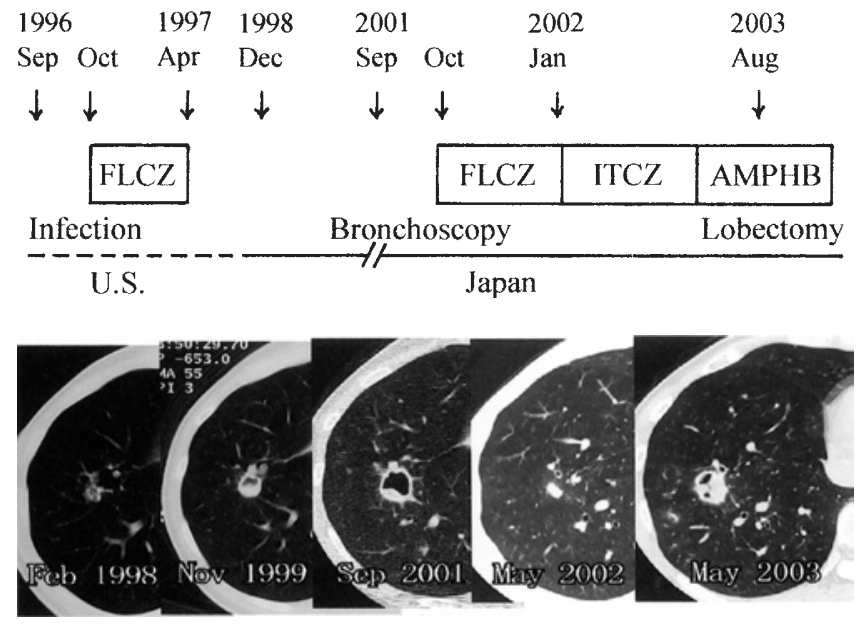

Figure 1. Clinical course. After the patient was diagnosed as coccidioidomycosis, a pulmonary nodule remained in the right lower lung field despite treatment with fluconazole for 6 months (CT in February 1998). In the course of 4-years' observation, the pulmonary nodule became larger and cavitated with fugus ball formation (CT in November 1999 and September 2001). Fiberoptic bronchoscopy in September 2001 revealed that the fungus ball consisted of $C$. immitis. Since 1.5 years of treatment with fluconazole and itraconazole resulted in ultimate failure after temporary effectiveness, we performed a lobectomy of the right lower lobe (CT in May 2002 and May 2003).

20, he was admitted to our hospital to identify the mycosis causing the fungus ball in the cavity, because fungus balls are usually formed by Aspergillus species and only rarely formed by $C$. immitis (3). Physical examination on admission was unremarkable except that his body temperature was 37.1 ${ }^{\circ} \mathrm{C}$. The serum C-reactive protein level was $0.7 \mathrm{mg} / \mathrm{ml}$. Serologic tests were positive for $C$. immitis (immunodiffu- sion method), but were negative for Aspergillus fumigatus and Cryptococcus neoformans. The serum level of $\beta$-Dglucan was within the normal limits. A chest radiograph demonstrated a thin-wall cavity measuring $1.9 \times 1.4 \mathrm{~cm}$ in the right lower lung field (Fig. 1, CT in September 2001 and Fig. 2). Cultures obtained by bronchial brushing grew mold, which was identified as $C$. immitis at the Research Center for Pathogenic Fungi and Microbial Toxicoses, Chiba University.

Not only fluconazole (300 mg daily p.o. at a total dose of $36 \mathrm{~g}$ ) but also itraconazole ( $200 \mathrm{mg}$ daily p.o. at a total dose of $78 \mathrm{~g}$ ) ultimately failed after temporary effectiveness as shown by the fact that this pulmonary cavity near the pleura grew larger in size with a thicker wall, and might have ruptured into the pleural space or produced a massive hemorrhage (Fig. 1; CT in May 2002 and May 2003). After antifungal treatment for a total of 18 months, he underwent resection of the right lower lobe and $50 \mathrm{mg}$ daily intravenous injection of amphotericin B at a total dose of nearly 1,000 $\mathrm{mg}$ at Toneyama National Hospital. The macroscopic view of the resected lung revealed a cavity $1.5 \times 1.0 \mathrm{~cm}$ in diameter encapsulated by a thick and fibrous wall (Fig. 3). It contained a gray fungus ball of $1.5 \times 1.0 \mathrm{~cm}$ in diameter that indented the pleura. Histopathological examination of the fungus ball showed numerous septate hyphae with terminal expansion. Although no typical spherules were found, the morphology of the fungus was compatible with $C$. immitis (Fig. 4). We did not cultivate the resected specimen because bronchial wash in September 2001 had already grown $C$. immitis. The fungus ball which did not involve the lung tissue was surrounded by numerous mononuclear cells and neutrophils. As the fungus ball grew inside the fibrous wall of the cavity, the fungus did not invade into the lung tissue at the periphery (data not shown). The patient has not presented any signs of recurrence as of July 2004.

Table 1. Laboratory Data on Admission (20 Sep. 2001)

\begin{tabular}{|c|c|c|c|c|c|}
\hline \multicolumn{2}{|l|}{ Hematology } & \multicolumn{4}{|c|}{ Chemistry } \\
\hline WBC & $3,140 / \mathrm{mm}^{3}$ & $\mathrm{Na}$ & $142 \mathrm{mEq} / \mathrm{l}$ & CRP & $0.7 \mathrm{mg} / \mathrm{dl}$ \\
\hline $\mathrm{Neu}$ & $56.1 \%$ & $\mathrm{~K}$ & $3.9 \mathrm{mEq} / \mathrm{l}$ & $\mathrm{IgG}$ & $773 \mathrm{U} / l$ \\
\hline Ly & $26.1 \%$ & $\mathrm{Cl}$ & $105 \mathrm{mEq} / \mathrm{l}$ & $\operatorname{IgA}$ & $\overline{145 \mathrm{U} / l}$ \\
\hline Mo & $9.2 \%$ & BUN & $8 \mathrm{mg} / \mathrm{dl}$ & $\operatorname{IgM}$ & $140 \mathrm{U} / l$ \\
\hline Eo & $7.6 \%$ & UA & $4.3 \mathrm{mg} / \mathrm{dl}$ & others & \\
\hline $\mathrm{Ba}$ & $1.0 \%$ & $\mathrm{Cr}$ & $0.7 \mathrm{mg} / \mathrm{dl}$ & anti-Aspergillus $\mathrm{Ab}$ & $(-)$ \\
\hline $\mathrm{RBC}$ & $481 \times 10^{4} / \mathrm{mm}^{3}$ & AST & $19 \mathrm{IU} / l$ & anti-Cryptococcus $\mathrm{Ab}$ & $(-)$ \\
\hline $\mathrm{Hb}$ & $15.2 \mathrm{~g} / \mathrm{dl}$ & ALT & $18 \mathrm{IU} / l$ & $\beta$-D-glucan & $4.2 \mathrm{pg} / \mathrm{ml}$ \\
\hline $\mathrm{Ht}$ & $45.0 \%$ & $\gamma \mathrm{GT}$ & $27 \mathrm{IU} / l$ & endotoxin & $1.7 \mathrm{pg} / \mathrm{ml}$ \\
\hline PLT & $10.5 \times 10^{4} / \mathrm{mm}^{3}$ & ALP & $101 \mathrm{IU} / \mathrm{l}$ & anti-C. immitis $\mathrm{Ab}$ & $(+)$ \\
\hline PT-\% & $105 \%$ & LD & $247 \mathrm{IU} / \mathrm{l}$ & (immunodiffusion method) & \\
\hline PT-INR & 0.97 & T-Bil & $0.3 \mathrm{mg} / \mathrm{dl}$ & & \\
\hline APTT & $38 \mathrm{sec}$ & D-Bil & $0.1 \mathrm{mg} / \mathrm{dl}$ & & \\
\hline Fib & $378 \mathrm{mg} / \mathrm{dl}$ & I-Bil & $0.2 \mathrm{mg} / \mathrm{dl}$ & & \\
\hline \multirow[t]{2}{*}{ FDP (D-dimer) } & $\overline{1.52 \mu \mathrm{g} / \mathrm{ml}}$ & $\mathrm{TP}$ & $6.6 \mathrm{~g} / \mathrm{dl}$ & & \\
\hline & & Alb & $4.2 \mathrm{~g} / \mathrm{dl}$ & & \\
\hline
\end{tabular}




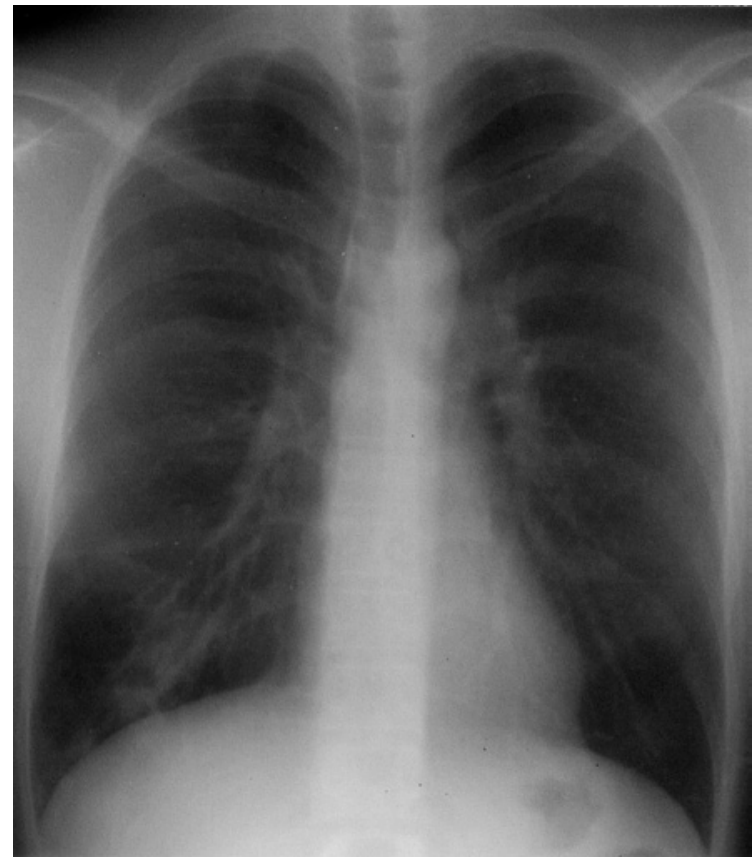

Sep 19, 2001

Figure 2. Chest radiograph on admission showing a thin-wall cavity in the right lower lung field.

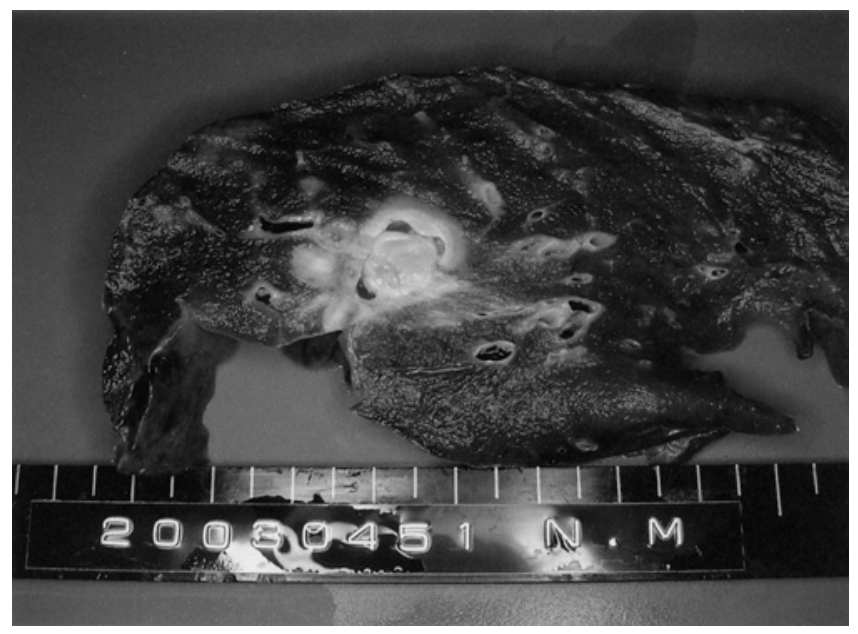

Figure 3. Macroscopic view of the resected lung demonstrates a cavity of $1.5 \times 1.0 \mathrm{~cm}$ diameter encapsulated by a thick and fibrous wall. It contains a gray fungus ball and indents the pleura.

\section{Discussion}

Although it is estimated that more than 100,000 new infections of $C$. immitis occur every year in the United States, only 31 cases of coccidioidomycosis had been reported as cases of imported mycosis as of 2001 in Japan (1). The number of cases has been sharply increasing, especially in the

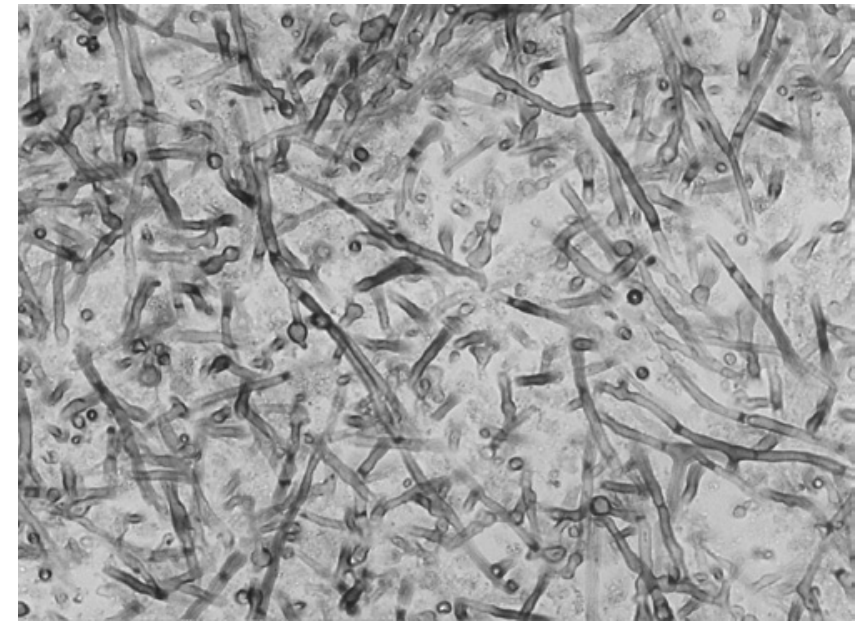

Figure 4. Histological examination of the fungus ball showed numerous septate hyphae with terminal expansion (Grocott stain $\times \mathbf{4 0 0})$.

last decade. Sixty percent of individuals infected with $C$. immitis are asymptomatic. The rest present with a mild to moderate flu-like illness (4). Half of symptomatic patients typically show pulmonary infiltrates associated with ipsilateral hilar lymphadenopathy on chest radiograph. Most symptoms disappear within a few weeks. Many patients with localized primary infections and no risk factors for complications may require only regular clinical assessment to assure resolution without treatment but azole anti-fungals for several months is considered for such a patient as our case complaining of night sweats persisting for more than 3 weeks (5). Approximately $5 \%$ of patients develop residual pulmonary lesions including small pulmonary nodules or thin-walled cavities near the pleura. Such patients are generally asymptomatic and the lesions in half of them regress spontaneously after a few years. However, $0.5-1.0 \%$ of the patients show extrapulmonary spread, including spread to the skin, bone, and central nervous system, and half of the cases of such spread may be fatal (6).

Neither detection of antibodies using enzyme-linked immunoassay nor cytological examination by fiberoptic bronchoscopy was contributory to a definitive diagnosis before admission of the patient described here to our hospital. Winn et al. reported that the majority of the cases of colonization and formation of a fungus ball in pleural cavities are due to Aspergillus species, and C. immitis presented radiographically as a fungus ball in only six published reports (3). Therefore we performed bronchoscopy again in an attempt to elucidate the origin of the fungus ball in the cavity. DiTomasso et al. reported that cytological examination alone detected C. immitis in only $35 \%$ of the patients whose bronchial wash had already grown $C$. immitis (7). Also in the present case, culturing of the sample was necessary to identify C. immitis. Although we did not detect typical spherules in 


\section{OSAKI et al}

the resected lung, the morphology of the hyphae and anthroconidia was compatible with $C$. immitis. The absence of typical spherules might have been due to the administration of amphotericin $\mathrm{B}$ before resection to suppress the infectivity of $C$. immitis. The titer of the $\mathrm{IgG}$ antibody reflects the clinical course of the disease. Approximately 50\% of the patients with chronic coccidioidal pulmonary cavities are seronegative by enzyme-linked immunoassay (8). We therefore utilized an immunodiffusion method as a more sensitive assay to prove a serological response to $C$. immitis (8).

Fluconazole is reported to be effective in $55 \%$ of 40 patients with chronic pulmonary lesion but $39 \%$ of responsive patients subsequently relapse (9). Cavities are considered to be candidates for resection if they are visible for longer than 2 years in association with symptoms, adjacent to pleura, or increasing in size $(4,5)$. In this case, we sequentially administered fluconazole and itraconazole for a year and a half despite unfavorable disease control since the patient hesitated to have a resection. We should have performed surgery earlier than we did, because if surgery is delayed, a cavity near the pleura might rupture and leak into the pleural space.

\section{Conclusion}

We do not have sufficient information about imported mycosis. However, we will certainly have increasing opportunities to encounter coccidioidomycosis, considering that the number of reports on this disease rose sharply in the last decade (1). As shown in this report, $C$. immitis is a possible cause of a fungus ball. In order to make a diagnosis of $C$. immitis, we should ask patients about the history of staying in the endemic region, and try to find spherules as a characteristic finding. We must also be aware that $C$. immitis is a potential infectious hazard to laboratory workers handling cultures.

\section{References}

1) Kamei K, Sano A, Kikuchi K, et al. The trend of imported mycoses in Japan. J Infect Chemother 9: 16-20, 2003.

2) Rohatgi PK, Schmitt RG. Pulmonary coccidioidal mycetoma. Am J Med Sci 287: 27-30, 1984.

3) Winn RE, Johnson R, Galgiani JN, Butler C, Pluss J. Cavitary coccidioidomycosis with fungus ball formation. Diagnosis by fiberoptic bronchoscopy with coexistence of hyphae and spherules. Chest 105: 412-416, 1994.

4) Chiller TM, Galgiani JN, Stevens DA. Coccidioidomycosis. Infect Dis Clin North Am 17: 41-57, viii, 2003.

5) Galgiani JN, Ampel NM, Catanzaro A, Johnson RH, Stevens DA, Williams PL. Practice guideline for the treatment of coccidioidomycosis. Infectious Diseases Society of America. Clin Infect Dis 30: 658661,2000

6) Stevens DA. Coccidioidomycosis. N Engl J Med 332: 1077-1082, 1995.

7) DiTomasso JP, Ampel NM, Sobonya RE, Bloom JW. Bronchoscopic diagnosis of pulmonary coccidioidomycosis. Comparison of cytology, culture, and transbronchial biopsy. Diagn Microbiol Infect Dis 18: 8387, 1994

8) Pappagianis D. Serologic studies in coccidioidomycosis. Semin Respir Infect 16: 242-250, 2001.

9) Catanzaro A, Galgiani JN, Levine BE, et al. Fluconazole in the treatment of chronic pulmonary and nonmeningeal disseminated coccidioidomycosis. NIAID Mycoses Study Group. Am J Med 98: 249-256, 1995. 